\title{
Radiolysis of Ascorbic Acid in Aqueous Solution
}

\author{
Hajime Ogura, Moriyasu Murata and Masaharu Kondo \\ Department of Chemistry, Faculty of Science, \\ Tokyo Metropolitan University, Tokyo
}

Received December 12, 1969

\section{Introduction}

A number of studies on the radiationinduced decomposition of several vitamins have been reported in connection with the application of ionizing radiation to the sterilization of foods and drugs. Ascorbic acid, a biologically important substance as vitamin $\mathrm{C}$, was found to be highly sensitive to radiation $^{1 \sim 4)}$.

The present paper reports the effect of ${ }^{60} \mathrm{Co}$ $\gamma$-radiatition on ascorbic acid in deaerated aqueous solution with no additives which are ordinally used to avoid the spontaneous oxidation of the solute during the irradiation. The reactivity of $\mathrm{H}$ atoms toward ascorbic acid was also determined by the scavenger method.

\section{Experimental}

Ascorbic acid (Merck reagent grade) was used in its original state. Alkaline permanganate aqueous solution was distilled three times and the obtained water was used to prepare the solution in every run. Five $\mathrm{m} l$ of aqueous solution of ascorbic acid was placed in a glass tube $13 \mathrm{~mm}$ i.d. which served as a irradiation cell. A break-seal was attached to the top of the tube when the gas analysis was required. The material connected with a vacuum line was outgassed by means of freeze-thaw recycles. The all irradiations were made at $17^{\circ} \mathrm{C}$ with ${ }^{60} \mathrm{Co}$ gamma rays at a dose rate of $1.44 \times$ $10^{18} \mathrm{eV} \mathrm{m} l^{-1} \mathrm{~h}^{-1}$. After irradiation, methaphosphoric acid was added to the solution to avoid the spontaneous oxidation of the solute during the course of the analysis. Ascorbic acid was determined by titration with 2,6-dichlorophenol indophenol. Dehydroascorbic acid was determined spectrophotometrically with 2,4-dinitrophenyl hydrazine. The determination of hydrogen radiolysed from the solution was carried out by gas chromatography using a molecular sieve $5 \mathrm{~A}$ column with argon as a carrier.

\section{Results}

Figure 1 presents our results of the radiolysis of deaerated $1 \mathrm{mM}$ ascorbic acid solution at its natural $\mathrm{pH}$ (3.6). The radiolytic yield of ascorbic acid, $\mathrm{AH}_{2}$, expressed in $G$ value is 3.6. Yields of dehydroascorbic acid, $G(\mathbf{A})$, and hydrogen, $G\left(\mathrm{H}_{2}\right)$, are 1.9 and 0.49 , respectively. As observed in Fig. 2, $G\left(-\mathrm{AH}_{2}\right)$ and $G\left(\mathbf{H}_{2}\right)$ are constant within the range of concentration from 0.5 to $10 \mathrm{~m} M$ for doses up to

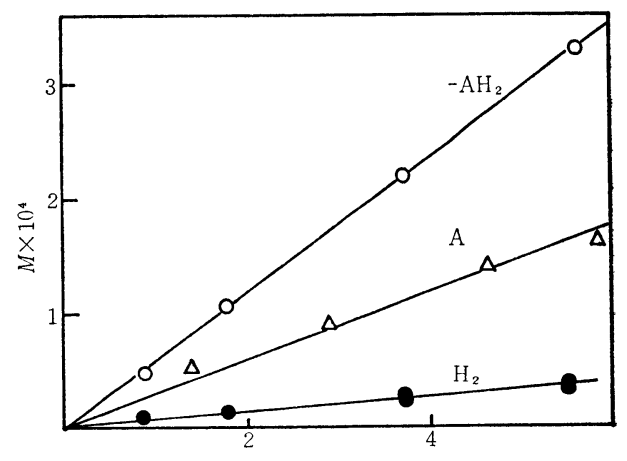

Dose $\left(\mathrm{eV} \cdot \mathrm{m} l^{-1}\right) \times 10^{-18}$

Fig. 1 Radiolysis of $1 \mathrm{~m} M$ ascorbic acid in deaerated system.

$\mathrm{O}$ : ascorbic acid $\left(\mathrm{AH}_{2}\right)$ radiolysed,

$\triangle$ : dehydroascorbic acid (A),

: hydrogen 
$6 \times 10^{18} \mathrm{eV} \mathrm{m} l^{-1}$, the highest dose used. It is also shown in Fig. 2 that the addition of $\mathrm{HPO}_{3}(6 \%)$ does not affect the hydrogen yield in the solution.

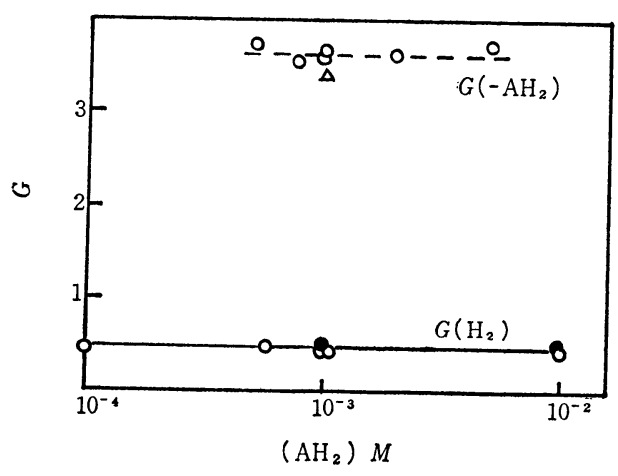

Fig. 2 Radiolytic yield as a function of initial concentration.

$O$ : aqueous solution,

: $6 \% \mathrm{HPO}_{3}$ solution,

$\triangle$ : $\mathrm{N}_{2} \mathrm{O}(3 \sim 10 \mathrm{mM})$ presented.

\section{Discussion}

The active species initially produced during the absorption of ionizing radiation in water are usually hydrated electrons, $\mathbf{H}$ atoms and $\mathrm{OH}$ radicals. It has been proposed by $\mathrm{RaO}^{4)}$ that $\mathbf{H}$ atom abstracts the hydrogen atom from ascorbic acid to form hydrogen by the following reaction.

$$
\mathrm{H}+\mathrm{AH}_{2} \rightarrow \mathrm{H}_{2}+\mathrm{AH}
$$

Since $G\left(\mathbf{H}_{2}\right)$ in the present experiment is nearly equal to the molecular yield of hydrogen, $\mathrm{GH}_{2}$, from irradiated water and independent of the concentrations of solute and hydrogen ion, it is unlikely that reaction (1) could be responsible for the formation of hydrogen. As to the fate of $\mathrm{H}$ atoms, an addition reaction onto an unsaturated bond, $-\mathrm{C}(\mathrm{OH})=\mathrm{C}(\mathrm{OH})-$, in ascorbic acid molecule may occur as follows.

$$
\mathrm{H}+\mathrm{AH}_{2} \stackrel{k_{2}}{\longrightarrow} \mathrm{AH}_{3}
$$

To determine the rate constant of reaction (2), 2-propanol was added to the solution containing nitrous oxide $(10 \mathrm{mM})$ which converts $\mathrm{e}_{\mathrm{aq}}^{-}$to $\mathrm{OH}$ radical very efficiently. If $\mathrm{H}$ atoms also react with 2-propanol according to reaction (3), equation (1) should describe the dependence of difference in hydrogen yield
$\left(\Delta G\left(\mathbf{H}_{2}\right)\right)$ in the solution containing nitrous oxide without and with 2-propanol on solute composition.

$$
\begin{gathered}
\mathrm{H}+\left(\mathrm{CH}_{3}\right)_{2} \mathrm{CHOH} \stackrel{k_{3}}{\longrightarrow} \mathrm{H}_{2}+\left(\mathrm{CH}_{3}\right)_{2} \mathrm{COH} \\
\frac{1}{\Delta G\left(\mathbf{H}_{2}\right)}=\frac{1}{G_{\mathrm{H}}}\left\{1+\frac{k_{2}\left(\mathbf{A H}_{2}\right)}{k_{3}(2 \text {-propanol })}\right\} \text { ( I ) }
\end{gathered}
$$

Figure 3 shows this to be the case and consequently $k_{2} / k_{3}=4.5$ and $G_{\mathrm{H}}=0.56$ which agree well with the accepted values ${ }^{5)}$. Taking $3.9 \times$ $10^{7} M^{-1} \cdot \sec ^{-1}$ for $\left.k_{3}^{6}\right), k_{2}$ is to be $2 \times 10^{8} M^{-1}$. $\sec ^{-1}$.

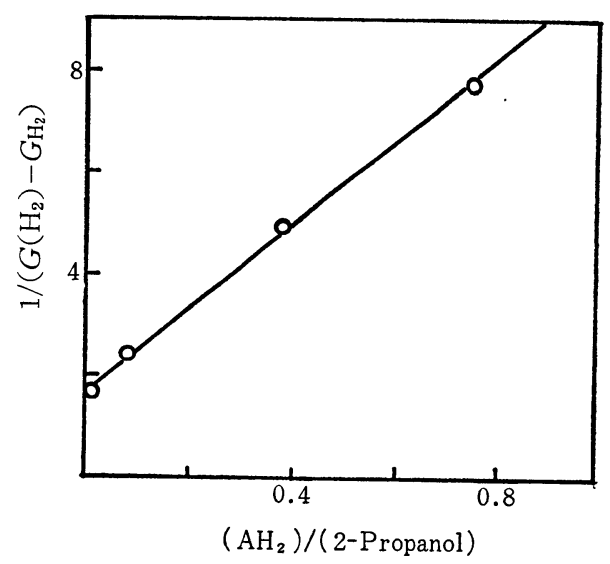

Fig. 3 Competition for $\mathrm{H}$ atom between ascorbic acid and 2-propanol plotted according to eq. ( I ).

Since the reactivity of $\mathbf{H}$ atoms, the typical reducing species, towards $\mathrm{AH}_{2}$ is fairly high as demonstrated above, it may be reasonable to assume that $e_{\mathrm{aq}}^{-}$reacts with $\mathrm{AH}_{2}$ in the same way as $\mathrm{H}$ atom does.

$$
\mathrm{e}_{\mathrm{aq}}^{-}+\mathrm{AH}_{2} \rightarrow \mathrm{AH}_{3}+\mathrm{OH}^{-}
$$

It has been found by us that $\mathrm{N}_{2} \mathrm{O}$ does not affect $G\left(-\mathbf{A H}_{2}\right)$. This should be due to that $\mathrm{OH}$ and $\mathrm{e}_{\mathrm{Bq}}^{-}$have nearly equal reactivity towards $\mathrm{AH}_{2}$. The reaction of $\mathrm{OH}$ with $\mathrm{AH}_{2}$ has been proposed as follows.

$$
\mathrm{OH}+\mathrm{AH}_{2} \rightarrow \mathrm{AH}+\mathrm{H}_{2} \mathrm{O}
$$

The rate constant of reaction (5) is $7.2 \times 10^{9}$ $M^{-1} \cdot \sec ^{-1}$ by pulse radiolysis ${ }^{7}$ and this large value is undoubtedly due to the fact that $\mathrm{AH}_{2}$ has easily oxidizable functional group.

As to the fate of these oxidized and reduced intermediates such as $\mathrm{AH}$ and $\mathrm{AH}_{3}$, the following reactions are taken into consideration. 


$$
\begin{aligned}
& 2 \mathrm{AH} \rightarrow \mathrm{A}+\mathrm{AH}_{2} \\
& \mathrm{AH}+\mathrm{AH}_{3} \rightarrow \mathrm{A}+\mathrm{AH}_{4} \\
& 2 \mathrm{AH}_{3} \rightarrow \mathrm{AH}_{2}+\mathrm{AH}_{4}
\end{aligned}
$$

If $\mathrm{e}_{\mathrm{aq}}^{-}, \mathrm{H}$ and $\mathrm{OH}$ would radiolyse $\mathrm{AH}_{2}$ as in reaction (2), (4) and (5), $G\left(-\mathrm{AH}_{2}\right)$ will be about 6 , which corresponds to the total radical yield $\left(G_{\mathrm{aq}}^{-}+G_{\mathrm{H}}+G_{\mathrm{OH}}\right)$. However, our observed $G\left(-\mathrm{AH}_{2}\right)(=3.6)$ is much lower than the total yield and this should be due to the reproduction of $\mathrm{AH}_{2}$ through reaction (6) and (8). The product $\mathrm{AH}_{4}$ is not yet identified but probably corresponds to gulono- $\gamma$-lactone which is oxidized to $\mathrm{AH}_{2}$ by means of Fenton's reagent according to Berends, et al. ${ }^{8}$ The formation of dehydroascorbic acid, $\mathrm{A}$, as was illustrated in Fig. 1, depends on the disproportionation by reaction (6) and on reaction (7). $G\left(-\mathrm{AH}_{2}\right)$ and $G(\mathrm{~A})$ cannot be estimated on the kinetic basis, because we cannot determine the proportion of rate constants of reaction (6), (7) and (8).

\section{References}

1) B.E. Procter and J.P. O'Meara: Ind. End. Chem., 43, 718 (1951)

2) N.F. Barr and C.G. King: J. Am. Chem. Soc., 78, 303 (1956)

3) H. Ogura and M. Kondo: Isotopes and Radiation (Tokyo), 2, 418 (1959)

4) B.S.N. Rao: Rad. Res., 5, 683 (1962)

5) J.W.T. Spinks and R.J. Woods: An Introduction to Radiation Chemistry, p. 259, John Wiley \& Sons, New York (1964)

6) G.R.A. Johnson and G. Scholes: The Chemistry of Ionization and Excitation (Proc. Conf. Rad. Chem. and Photochem., Newcastle upon Tyne, 1966) p. 253, Taylor \& Francis, London (1967)

7) M. Ebert, J.P. Keene, A.J. Swallow and J.H. Baxendale: Pulse Radiolysis, p. 117, Academic Press, New York, London (1965)

8) W. Berends and J. Konings: Recueil, 74, 1365 (1955) 